\title{
ACE-inhibition prevents postischemic coronary leukocyte adhesion and leukocyte-dependent reperfusion injury
}

\author{
Christian Kupatt a , Helmut Habazettl ${ }^{\mathrm{b}}$, Stefan Zahler ${ }^{\mathrm{a}}$, Christian Weber ${ }^{\mathrm{c}}$, \\ Bernhard F. Becker ${ }^{\text {a }, *}$, Konrad Messmer ${ }^{\text {b }}$, Eckehart Gerlach ${ }^{\text {a }}$ \\ ${ }^{a}$ Department of Physiology, Ludwig-Maximilians-University, Pettenkoferstr. 12, 80336 Munich, Germany \\ ${ }^{\mathrm{b}}$ Institute for Surgical Research, University of Munich, Munich, Germany \\ ${ }^{c}$ Institute for Cardiovascular Disease, University of Munich, Munich, Germany
}

Received 17 March 1997; accepted 18 June 1997

\begin{abstract}
Objective: Polymorphonuclear leukocytes (PMN), retained in the microvascular bed, can contribute to postischemic myocardial reperfusion injury. Since a beneficial effect of ACE-inhibition on reperfusion injury has been reported, we investigated the impact of cilazaprilat on PMN dependent reperfusion injury in isolated guinea pig hearts. Methods: Hearts ( $n=5$ per group) were subjected to 15 min of ischemia. Immediately thereafter, a bolus of PMN was injected into the coronary system. External heart work (EHW) and total cardiac nitric oxide release were measured. For microscopic evaluation, hearts received rhodamine $6 \mathrm{G}$ labelled PMN after ischemia, were arrested 5 min later and further perfused with FITC dextran $(0.1 \%)$. Localization of retained PMN was assessed by fluorescence microscopy. Leukocyte activation was studied by FACS analysis of the adhesion molecule CD11b before and after coronary passage of the PMN. The ACE-inhibitor cilazaprilat (Cila, $2 \mu \mathrm{M}$ ) and the NO-synthase inhibitor nitro-L-arginine (NOLAG, $10 \mu \mathrm{M}$ ) were used to modulate nitric oxide formation of the heart. Results: Postischemic EHW recovered to $67 \pm 5 \%$ (controls) and $64 \pm 6 \%$ (Cila) of the preischemic value. Addition of PMN severely depressed recovery of EHW $(39 \pm 2 \%)$ and NO release $(39 \pm 6 \%$ of the preischemic value). Simultaneously, ischemia led to a substantial increase in postcapillary PMN adhesion (from $21 \pm 5$ to $172 \pm 27 \mathrm{PMN} / \mathrm{mm}^{2}$ surface) and CD11b-expression of the recovered PMN (3-fold). Cila attenuated postischemic PMN adhesion $\left(83 \pm 52 \mathrm{PMN} / \mathrm{mm}^{2}\right)$ and activation of PMN, whereas it improved recovery of work performance $(64 \pm 4 \%)$ and NO release $(65 \pm 4 \%)$ in the presence of PMN. Conversely, NOLAG increased PMN adhesion $\left(284 \pm 40 \mathrm{PMN} / \mathrm{mm}^{2}\right)$ and myocardial injury. We conclude that ACE-inhibition prevents leukocyte dependent reperfusion injury mainly by inhibition of postcapillary leukocyte adhesion. The effect may be mediated by NO, given the proadhesive effect of NOLAG. (C) 1997 Elsevier Science B.V.
\end{abstract}

Keywords: Cilazaprilat; Coronary microcirculation; Fluorescence microscopy; Leukocyte adhesion; Myocardial stunning; Nitric oxide

\section{Introduction}

Reperfusion of an occluded coronary artery is the only known therapeutic strategy preventing myocardial necrosis if applied in time. Nevertheless, reperfusion itself can induce a certain damage, i.e. reperfusion injury. Clinically it may appear as reversible decrease of myocardial contractility (stunning) [1,2], or as reversible loss of endothelial function [3]. However, both deficits may persist in single cases, if microcirculatory perfusion is impaired for a pro-

\footnotetext{
* Corresponding author. Tel. (+49-89) 5996402; Fax (+49-89) 5996378; E-mail u721101@sunmail.lrz-muenchen.de
}

longed time, as indicated by low-reflow or no-reflow phenomena $[4,5]$.

Polymorphonuclear granulocytes (PMN) which are recruited and activated in the reperfused myocardium can contribute to myocardial reperfusion injury in patients [6], as well as in a variety of models in vivo [7-11] and in situ $[12,13]$. Two alternative mechanisms are considered relevant for PMN retention in microcirculatory beds. Capillary plugging of PMN as physical process is caused by narrowing of capillary lumina and/or reduced leukocyte elasticity [14]. On the other hand, neutrophils may selectively inter-

Time for primary review 51 days. 
act with endothelial cells through adhesion molecules, as demonstrated after myocardial ischemia $[15,16]$. The adhesion process of PMN on endothelial cells generally follows a two-step pattern [17], a slow movement of a leukocyte on the endothelial cell wall (rolling) and subsequent firm adhesion (sticking) (for review see [18])

Inhibition of the angiotensin I converting enzyme (ACE), which represents a widely used pharmacologic intervention in patients with coronary artery disease, was beneficial against myocardial reperfusion injury in several distinct models [19-23]. ACE-inhibition has been shown to reduce bradykinin degradation, in turn stimulating nitric oxide synthase $[24,25]$. Since NO mitigates PMN adhesion in other vascular beds [26], we wanted to investigate the cardioprotective potential of ACE-inhibition during postischemic reperfusion in an isolated heart model where the contribution of PMN to reperfusion injury can be distinguished from other sources of postischemic damage. To evaluate the effect, we assessed pre- and postischemic myocardial and endothelial function in terms of external heart work and endothelial nitric oxide release, respectively. In addition, we performed in situ fluorescence microscopy to characterize the precise localization and quantity of postischemically retained PMN. To determine the importance of NO, ACE inhibition was consistently compared with a nitric oxide synthase inhibitor (NOLAG) in further experiments.

\section{Methods}

\subsection{Materials}

Cilazaprilat, which was a gift of Hofmann-La Roche (Basel, Switzerland), was used at $2 \mu \mathrm{M}$. Nitro-L-arginine (NOLAG, Sigma Chemie, Deisenhofen, FRG) was used at $10 \mu \mathrm{M}$, rhodamine 6G (Sigma Chemie) was used to label PMN. Percoll for PMN separation and fluorescein isothiocyanate-dextran (FITC dextran, MW 150000) were purchased from Pharmacia Biotech AB, Uppsala, Sweden. Monoclonal antibodies against CD15 (Miltenyi, Cologne, FRG) were used for human PMN separation, whereas CD11b analysis was performed with monoclonal antibodies from Exalpha (Boston, MA).

\subsection{PMN preparation}

\subsubsection{Homologous}

For in situ microscopy experiments, PMN (guinea pig) were isolated as previously described [27,28]. Using HES sedimentation, Percoll separation and red cell lysis with distilled water, a pellet of at least $95 \%$ pure, $99 \%$ viable PMN was obtained. PMN were incubated with rhodamine 6G (0.005\%, 10 min), counted (Coulter Counter ZM with Channelyzer, Coulter Electronics, King, NC, USA), and adjusted to the required cell content per $\mathrm{ml}\left(10 \times 10^{6} / \mathrm{ml}\right)$.

\subsubsection{Human}

In order to study PMN activation by flow-cytometrical surface analysis, a heterologous source of PMN was used, because no guinea pig antibody against CD11b was available to the best of our knowledge. Human PMN were isolated from peripheral venous blood of healthy volunteers by magnetic bead separation, as described elsewhere [29]. Briefly, purification of neutrophils from $10 \mathrm{ml}$ human blood (EDTA $0.1 \%$ ) was achieved by magnetic separation of cells previously labelled with a CD15 antibody carrying iron microbeads (Miltenyi Biotech, Bergisch Gladbach, FRG). Cells were analyzed by flow cytometry (FACScan, Becton Dikinson, San Jose, CA, USA) and proved to be 99\% PMN. Cells were resuspended in Tyrode's solution ( $\mathrm{pH} 7.40$ ), counted and diluted to $10 \times 10^{6}$ cells $/ \mathrm{ml}$. As established in an earlier study, the cells prepared by these two techniques are not prestimulated and of comparable reactivity [29].

\subsection{Heart preparation}

The care of the animals and all experimental procedures conform with the Guide for the Care and Use of Laboratory Animals. Guinea pig hearts were isolated and perfused as previously described. Briefly, animals (male, 200-250 g) were anesthetized (Ketanest $200 \mathrm{mg} / \mathrm{kg}$ body weight) and decapitated. The hearts were arrested with cold saline and removed quickly from the thorax. The aorta was canulated and retrogradely perfused with a modified Krebs-Henseleit buffer gassed with $97 \% \mathrm{O}_{2}$ and $3 \% \mathrm{CO}_{2}$ $\left(37^{\circ} \mathrm{C}, \mathrm{pH} 7.40\right)$.

For microscopic evaluation (Langendorff preparation) caval, azygos and pulmonary veins were ligated. Retrograde perfusion was maintained throughout the experiment and in situ microscopic period.

The working heart preparation was performed, as previously described [30]. The caval and azygos veins were ligated. Pulmonary venous entry was used for a canula which, in the working mode of the heart, provided orthograde access for the perfusate. In the perfusion apparatus it was possible to switch between non-working (Langendorff) mode and working heart mode. External heart work was calculated as the sum of pressure-volume work (developed aortic pressure $\times$ cardiac output) and acceleration work [29].

\subsection{Experimental protocols}

Immediately after canulation, hearts were perfused at constant aortic pressure $\left(80 \mathrm{~cm} \mathrm{H}_{2} \mathrm{O}\right)$ for 5 min to finish preparation. At this point, hearts were assigned either to microscopic evaluation or to functional studies including determination of external heart work, nitric oxide release and leukocyte activation.

In experiments assessing external heart work, pressure volume work was performed (preload $12 \mathrm{~cm} \mathrm{H}_{2} \mathrm{O}$, after- 


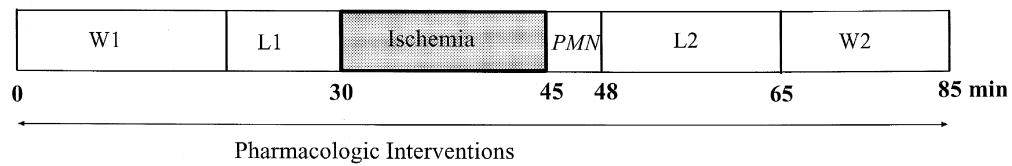

B) In Situ Microscopy

\begin{tabular}{lc|l|l|l|}
\hline & Preischemic & Ischemia & $P M N$ & In situ microscopy \\
\hline $\mathbf{0}$ & $\mathbf{1 0}$ & $\mathbf{3 0}$ & $\mathbf{4 5} \quad \mathbf{4 8} \mathrm{min}$
\end{tabular}

Pharmacologic Interventions

Fig. 1. L1 = Langendorff period $1(5 \mathrm{ml} / \mathrm{min}$ volume constant perfusion); L2 = Langendorff period $2(5 \mathrm{ml} / \mathrm{min})$; W1=Working period 1 ; $\mathrm{W} 2=$ Working period 2; PMN $=$ post-ischemic application of $10^{7} \mathrm{PMN}$.

load $60 \mathrm{mmHg}$ ) for $20 \mathrm{~min}$ (W1, see Fig. 1A), followed by $10 \mathrm{~min}$ of constant-flow Langendorff perfusion $(5 \mathrm{ml} / \mathrm{min})$. After ischemia $\left(15 \mathrm{~min}, 37^{\circ} \mathrm{C}\right)$, hearts were initially reperfused in the non-working Langendorff mode $(5 \mathrm{ml} / \mathrm{min}$, $20 \mathrm{~min}$ ) before a second period of external heart work at the given conditions was begun.

For microscopic evaluation, perfusion was continued at constant coronary flow of $5 \mathrm{ml} / \mathrm{min}$ for $30 \mathrm{~min}$ (see Fig. 1B). Usually, global ischemia was next imposed for 15 min, during which hearts were immersed in warm perfusate $\left(37^{\circ} \mathrm{C}, \mathrm{pH} 7.40\right)$. Thereafter, reperfusion was started, again at $5 \mathrm{ml} / \mathrm{min}$, lasting for $5 \mathrm{~min}$ in all experiments. PMN were applied when reperfusion was started and recovered in the coronary effluent for $3 \mathrm{~min}$ for further analysis. Cold cardioplegic solution was then infused to arrest the heart. After being placed on a stage displaying the left ventricle area to the microscope, FITC-infusion was begun.

Most experimental series involved 10 hearts, 5 of each used in parallel experiments for either microscopic or functional evaluation. Time matched 'control' experiments were performed without ischemia, $10^{7} \mathrm{PMN}$ being applied after 45 min of perfusion. In the 'ischemia' series PMN were infused in the first min of reperfusion after $15 \mathrm{~min}$ of ischemia. In addition, one working heart group was subjected to ischemia without PMN infusion. To assess the role of endogenous $\mathrm{NO}$, cilazaprilat $(2 \mu \mathrm{mol} / \mathrm{l})$ and nitroL-arginine (NOLAG, $10 \mu \mathrm{mol} / \mathrm{l}$ ) were added to the perfusate in order to stimulate (indirectly) or inhibit NO synthase activity in experiments including ischemia.

\subsubsection{Nitric oxide release}

In working heart experiments, a nitric oxide sensitive, microtip probe (WPI, Sarasota, FL, USA) was placed into the pulmonary artery directly behind the pulmonary valve, the tip of the NO sensor being inserted into a T-tube. Isothermal conditions were achieved by immersing preparations in Tyrode's solution at $37^{\circ} \mathrm{C}$. Validation of the probe recording in the coronary effluent was performed using bradykinin to generate NO by the endothelium, and erythrocyte-borne hemoglobin (hematocrit 5\%) to sequester NO (data not shown). Reproducible stimulation and suppression of the signal to zero were observed, respectively.

Considerable variability of basal release of $\mathrm{NO}$ between hearts during preischemic volume constant perfusion $\left(\mathrm{L}_{1}\right)$ was found in all groups. Comparability of volume constant perfusion and working heart mode (different flow rates) was achieved by calculating $\mathrm{NO}$ release per minute per $\mathrm{g}$ dry weight of the hearts from the concentration data. Postischemic NO release is given in percent of preischemic values.

\subsubsection{Fluorescence microscopy}

For the purpose of in situ microscopy hearts were arrested by cold cardioplegic solution (potassium 28 $\mathrm{mmol} / \mathrm{l})$. Thereafter they were placed on a specially designed microscopic stage holder, the surface of the left ventricle being exposed to a microscope (Ploemopak, Leitz, Wetzlar, FRG) with a 10-fold objective (L10, 0.22 Aperture, Leitz). Images were generated by a charge coupled device camera (COHU 4400, Prospective Measurements, San Diego, CA). To analyze vessel distribution fluorescein isothiocyanate dextran (FITC $0.1 \%$ ) was infused $(15 \mathrm{ml} / \mathrm{h}$ ) and excited by epi-illumination with a H130 mercury light source and filtered with an $\mathrm{I}_{2,3}$ filter block (Leitz, excitation/emission spectra: 450-490/>515 nm). The distribution of PMN was studied under a rhodamine $6 \mathrm{G}$ selective $\mathrm{N}_{2}$ filter block (Leitz, excitation/emission spectra: 515$560 />580 \mathrm{~nm}$ ).

This method allowed for localization of PMN with respect to the vascular lumen. Capillary plugging was assessed by counting PMN in regions devoid of venules. 5 fields with an area of $1.2 \mathrm{~mm}^{2}$ each were studied per heart. Postcapillary venular adhesion was observed in venules of 10-50 $\mu \mathrm{m}$ diameter (small venules, $n=8-10$ per heart). 


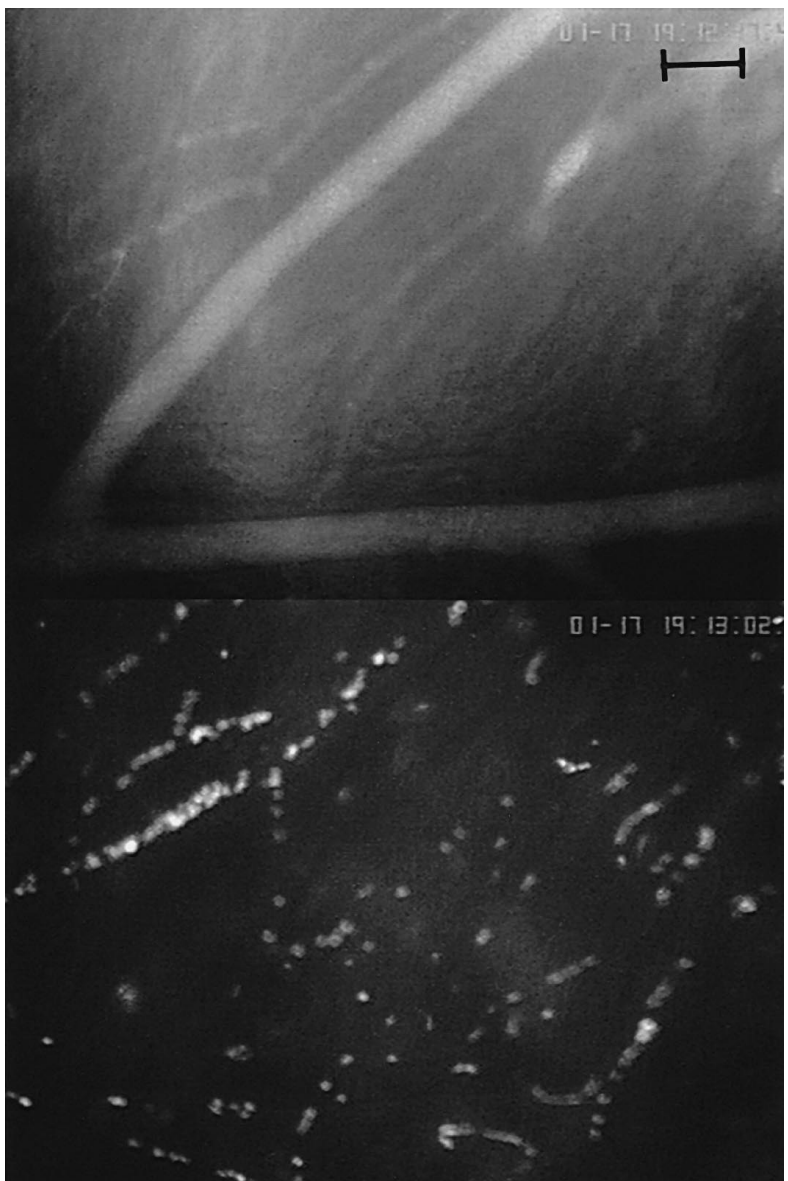

Fig. 2. Example of PMN retention in reperfused epicardial vessels. Scale bar: $100 \mu \mathrm{m}$. The upper panel demonstrates distribution of vessels (FITC-dextran $0.1 \%$ ), two branches of arteriolae marked by white arrows. Lower panel shows pattern of leukocyte retention. Plenty of PMN are localized in venular vessel lumina, while no adhesion was found in arteriolae.

In addition, venules of 50-300 $\mu \mathrm{m}$ diameter (large venules, $n=4-5$ per heart) were investigated. Fig. 2 demonstrates FITC and rhodamine fluorescence of an epicardial surface of a postischemic heart, showing substantial leukocyte adhesion in venules, but not in arterioles.

\subsubsection{Flow cytometry analysis}

To further assess the degree of activation induced during coronary passage, PMN were analyzed in a flow cytometer (FACScan, Becton Dickinson, San Jose, CA, USA) using a phycoerythrin (PE) fluorescence-labelled monoclonal CD11b-antibody (Moab) which bound to the PMN epitope CD11b, part of the heterodimeric adhesion molecule CD11b/CD18 (MAC-1). Forwardscatter analysis and gating of the PMN range provided analysis of a homogeneous PMN population. Isotype controls with a nonbinding, fluorescence labelled Moab (anti-mouse IgG1) served to determine nonspecific binding and background fluorescence. Activation of PMN was expressed in relation to the basal values before coronary passage. Data analysis of 10000 events was performed with Lysis II software on a Hewlett Pakard system.

\subsection{Statistical methods}

The results are given as mean \pm SEM. Statistical analysis was performed with one way analysis of variance (ANOVA). Whenever a significant effect was obtained with ANOVA, we performed multiple comparison tests between the groups using Dunn's test (Sigmastat statistical program). Differences between groups were considered significant for $p<0.05$.

\section{Results}

Since beneficial effects of ACE-inhibitors have been demonstrated following myocardial hypoperfusion in vivo, we studied the effects of cilazaprilat on PMN dependent myocardial reperfusion injury.

\subsection{Functional reperfusion injury}

\subsubsection{Coronary and myocardial function}

At a concentration of $2 \mu \mathrm{M}$, cilazaprilat evoked no change in coronary flow $(\mathrm{CF})$ or coronary perfusion pressure (CPP) preischemically (Table 1), in contrast to NOLAG which, at $10 \mu \mathrm{M}$, elevated CPP. After ischemia, CPP first decreased during postischemic dilation, before rising above preischemic values in all groups. Fittingly, $\mathrm{CF}$ in $\mathrm{W}_{2}$ was significantly suppressed vs. the preischemic value in all groups (Table 1). The same tendency existed in the presence of cilazaprilat, excluding a major hemodynamic effect of the drug. In contrast, NOLAG blunted the postischemic dilation and decreased $\mathrm{CF}$ in $\mathrm{W}_{2}$ more extensively than PMN alone.

Values of external heart work prior to ischemia for the various experimental groups did not differ significantly (Table 1). Application of a PMN bolus without ischemia caused only a slight detriment of external heart work (Control PMN, Fig. 3). After ischemia alone, recovery of EHW deteriorated to $67 \pm 5 \%$ of the initial value. Ischemia and a PMN bolus acted synergistically, reducing recovery of EHW to $39 \pm 6 \%$. This level was further decreased to $29 \pm 6 \%$ in the presence of NOLAG $(1 \mu \mathrm{M})$. If the concentration of NOLAG was increased to $10 \mu \mathrm{M}$, no recovery could be measured due to ventricular fibrillation and pump failure. Cilazaprilat $(2 \mu \mathrm{M})$, however, counteracted the detrimental effects of PMN without ( $64 \pm$ $4 \%)$ or in the presence of NOLAG $(1 \mu \mathrm{M}, 41 \pm 3 \%)$, whereas it did not influence the recovery of reperfused hearts not confronted with PMN (65 $\pm 4 \%$ recovery).

Thus, postischemic myocardial performance was related to the absence or presence of PMN. Cilazaprilat effectively prevented PMN-induced loss of function, NOLAG augmented it. 


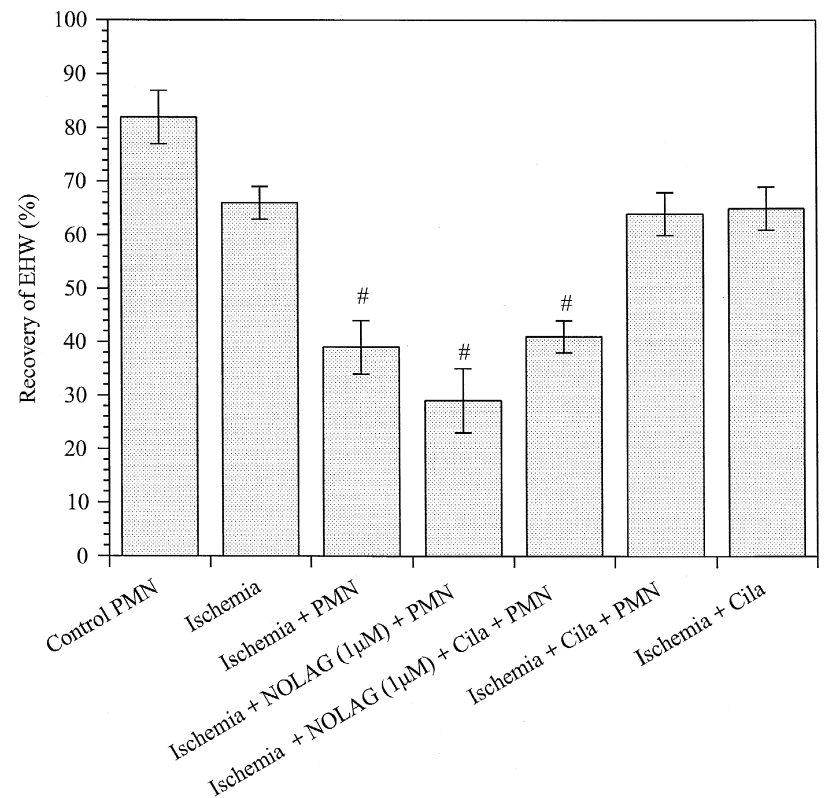

Fig. 3. Recovery of external heart work in Working Phase 2, given in percent of results in Working Phase 1 . Control PMN $=$ time matched control experiments. Ischemia $=15 \mathrm{~min}$ of warm ischemia, Ischemia + $P M N=$ bolus of $5 \times 10^{6}$ PMN given with the beginning of reperfusion, Ischemia $+N O L A G+P M N=$ postischemic PMN bolus in the presence of $1 \mu \mathrm{M}$ Nolag. Ischemia $+N O L A G+$ Cila $+P M N=$ postischemic PMN bolus in the presence of $1 \mu \mathrm{M}$ Nolag and $2 \mu \mathrm{M}$ cilazaprilat. Ischemia + Cila $+P M N=$ postischemic PMN bolus in the presence of cilazaprilat. Ischemia + Cila $=$ Ischemia and reperfusion in the presence of cilazaprilat.

\subsubsection{Studies on nitric oxide release}

Release of nitric oxide is a specific feature of the endothelium, regulating vascular resistance. We investigated endothelial integrity by measuring $\mathrm{NO}$ release of the whole coronary system. Isolated guinea pig hearts performing pressure-volume work prior to ischemic challenge $\left(\mathrm{W}_{1}\right)$ released NO into the coronary effluent at variable, but not significantly different rates (Table 1). The concentration approximated 2-3 $\mu \mathrm{M}$. Preischemic 'basal' nitric
Table 2

Nitric oxide release prior to ischemia in the different experimental groups

\begin{tabular}{lll}
\hline & $\begin{array}{l}\text { NO release in } \mathrm{W}_{1} \\
(\mathrm{nmol} / \mathrm{min} / \mathrm{g})\end{array}$ & $\begin{array}{l}\text { NO release in } \mathrm{L}_{1} \\
(\mathrm{nmol} / \mathrm{min} / \mathrm{g})\end{array}$ \\
\hline Ischemia & $34.0 \pm 2.4$ & $9.0 \pm 1.8^{\mathrm{a}}$ \\
Ischemia + PMN & $23.7 \pm 9.6$ & $7.6 \pm 3.0^{\mathrm{a}}$ \\
Ischemia + PMN + Cila & $20.3 \pm 1.9$ & $6.0 \pm 0.1^{\mathrm{a}}$
\end{tabular}

$\mathrm{W}_{1}=$ Work Phase $1, \mathrm{~L}_{1}=$ Langendorff Phase 1 ,

${ }^{\mathrm{a}} p<0.05 \mathrm{v}$. value in $\mathrm{W}_{1}(n=5$ per group $)$.

oxide release in hearts perfused in the Langendorff mode $\left(\mathrm{L}_{1}\right)$ was markedly lower than during work $\left(\mathrm{W}_{1}\right.$, Table 2$)$. Surprisingly, cilazaprilat had no discernible effect on preischemic NO release, as already suggested by coronary hemodynamics (Table 1). Since no in situ calibration of the NO-flow probe was possible in the presence of NOLAG, no quantitative data were obtained for these experimental groups. In hearts receiving PMN without preceding ischemia (control + PMN), the capability to form NO was only slightly attenuated over time, the difference between $\mathrm{L}_{1}$ and $\mathrm{L}_{2}$ amounting to $0.5 \mathrm{nmol} / \mathrm{min} / \mathrm{g}$ (results not shown).

To correct for differences of NO release due to the mode of perfusion, postischemic values of $\mathrm{L}_{2}$ or $\mathrm{W}_{2}$ in Fig. 4 are given in percent of the preischemic values obtained in the same mode $\left(\mathrm{L}_{1}\right.$ or $\left.\mathrm{W}_{1}\right)$. In hearts subjected to ischemia, a transient increase in NO release after $5 \mathrm{~min}$ of reperfusion was displayed in most groups, which was most prominent in the presence of cilazaprilat (Fig. 4). Although the postischemic increase in NO release lasted only a few minutes, it was during this period that PMN application into the coronaries occurred in the present experiments. Over the subsequent $20 \mathrm{~min}$, NO release decreased by $30 \%$ on average. The drop was found to be most pronounced in the PMN group $(46 \pm 1 \%$ of the preischemic value). This leukocyte-dependent effect was prevented by cilazaprilat, whereas no effect of cilazaprilat was detected in hearts not subjected to PMN infusion.

Table 1

Hemodynamic characterization of the experimental groups

\begin{tabular}{|c|c|c|c|c|c|c|c|}
\hline & $\begin{array}{l}\text { EHW (W1) } \\
(\mathrm{mJ} / \mathrm{min} / \mathrm{g})\end{array}$ & $\begin{array}{l}\mathrm{CF} 1 \\
(\mathrm{ml} / \mathrm{min})\end{array}$ & $\begin{array}{l}\mathrm{CF} 2 \\
(\mathrm{ml} / \mathrm{min})\end{array}$ & $\begin{array}{l}\mathrm{CPP}_{\text {basal }} \\
(\mathrm{mmHg})\end{array}$ & $\begin{array}{l}\mathrm{CPP}_{5 \text { min }} \\
(\mathrm{mmHg})\end{array}$ & $\begin{array}{l}\mathrm{CPP}_{20 \min } \\
(\mathrm{mmHg})\end{array}$ & $\begin{array}{l}\text { NO release } \\
(\mathrm{nmosal} / \mathrm{min} / \mathrm{g})\end{array}$ \\
\hline Control & $231 \pm 21$ & $8.0 \pm 0.6$ & $6.7 \pm 0.3$ & $29.5 \pm 1.3$ & - & - & - \\
\hline Ischemia & $182 \pm 19$ & $9.0 \pm 0.5$ & $7.8 \pm 0.4^{\mathrm{a}}$ & $27.0 \pm 1.2$ & $26.8 \pm 2.0$ & $35.6 \pm 4.3$ & $9.0 \pm 1.8$ \\
\hline Ischemia + PMN + NOLAG & $226 \pm 18$ & $9.0 \pm 0.4$ & $4.9 \pm 0.2^{\mathrm{a}}$ & - & $23.2 \pm 1.1$ & $43.4 \pm 7.1$ & n.d. \\
\hline Ischemia + PMN + Cila + NOLAG & $181 \pm 17$ & $9.7 \pm 0.4$ & $6.3 \pm 0.4^{\mathrm{a}}$ & - & $20.4 \pm 1.8$ & $30.0 \pm 4.0$ & n.d. \\
\hline Ischemia + PMN + Cila & $192 \pm 33$ & $8.4 \pm 0.6$ & $6.3 \pm 0.5^{\mathrm{a}}$ & $28.0 \pm 2.3$ & $28.0 \pm 2.3$ & $35.7 \pm 8.3$ & $6.0 \pm 1.8$ \\
\hline
\end{tabular}

EHW $(\mathrm{W} 1)=$ External heart work in working Phase $1, \mathrm{CF} 1=$ Coronary flow in $\mathrm{W} 1, \mathrm{CF} 2=$ Coronary flow in $\mathrm{W} 2, \mathrm{CPP}_{\text {basal }}=\mathrm{Coronary}_{\text {perfusion pressure }}$ in Langendorff Phase $1, \mathrm{CPP}_{5}=\mathrm{CPP}$ after $5 \mathrm{~min}$ of reperfusion, $\mathrm{C} \mathrm{PP} 20=\mathrm{CPP}$ after $20 \mathrm{~min}$ of reperfusion. Mean $\pm \mathrm{SEM}$.

${ }^{\mathrm{a}} p<0.05$ v. CF1,

${ }^{\mathrm{b}} p<0.05$ v. $\mathrm{CPP}_{\text {basal }}$,

n.d. $=$ not detectable,

$-=$ not measured. 


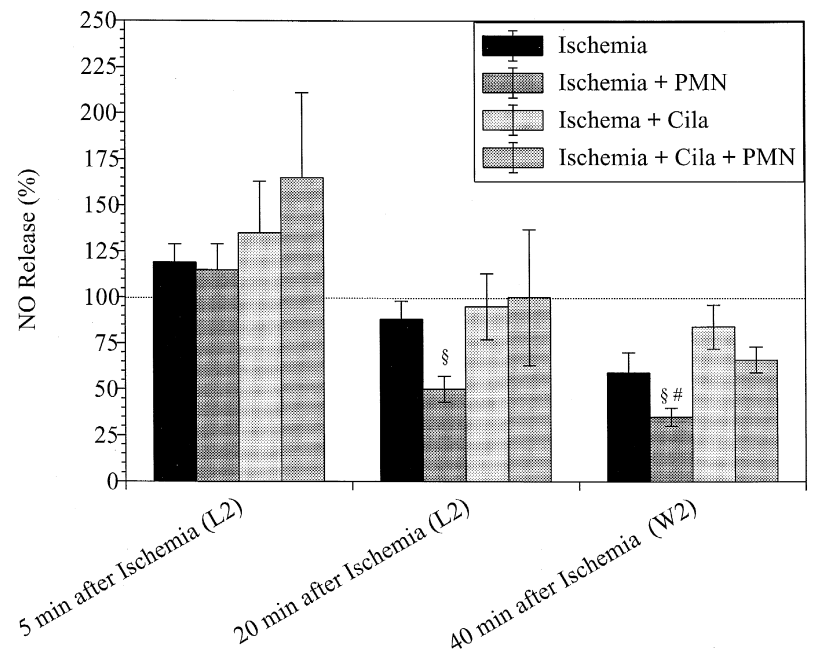

Fig. 4. Coronary nitric oxide release measured by an NO-flow probe (WPI) in strict isothermia $\left(37^{\circ} \mathrm{C}\right)$. Values are given in percent of preischemic level (see Table 2). Ischemia $=15 \mathrm{~min}$ of warm ischemia, $P M N$ $=$ bolus of $5 \times 10^{6}$ PMN given with the beginning of reperfusion, Cila $=2 \mu$ M Cilazaprilat. $\S=p<0.05$ v. 5 min after ischemia; $\#=p<$ $0.05 \mathrm{v}$. cilazaprilat groups at the same time.

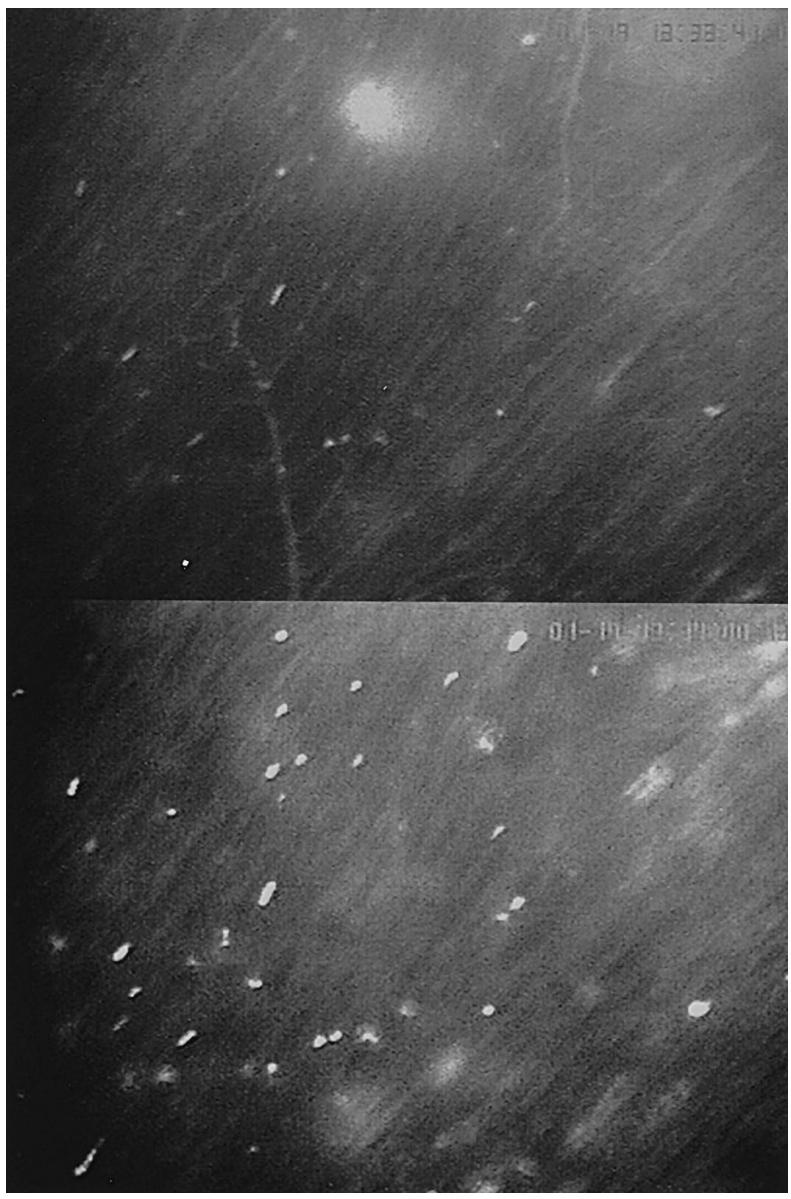

Fig. 5. Example of postischemic PMN plugging in capillaries (Ischemia group). Upper Panel: FITC-fluorescence picture, $1.2 \mathrm{~mm}^{2}$ field. Lower Panel: Rhodamine 6G fluorescence picture showing PMN in capillaries.
Experiments with inhibition of NO synthases (NOLAG, 10 $\mu \mathrm{M})$ displayed neither an increase after 5 min nor a decrease after $20 \mathrm{~min}$ of reperfusion (data not shown). However, the lack of reaction of the probe after challenge with an erythrocyte bolus suggested that no endogenous NO formation was taking place under this condition anyway.

In work phase 2 , hearts released only about half $(55 \pm$ $0.5 \%$ ) of the NO detected in $\mathrm{W}_{1}$ (Fig. 4). Hearts in the ischemia PMN group released less nitric oxide than in the absence of PMN. Pretreatment with cilazaprilat prevented this effect of PMN but did not restore postischemic NO release to the preischemic level. The relative conservation of the postischemic NO release through cilazaprilat was not related to a higher level of NO preischemically (Table $1)$.

\subsection{Leukocyte adhesion and activation after ischemia}

\subsubsection{Capillary plugging}

PMN can be trapped in the microcirculatory system through plugging in capillaries, where the vessel diameter is reduced to about $10 \mu \mathrm{m}$ and less. As shown in one example (Fig. 5), ischemia induced some plugging of PMN in epicardial capillaries. This impression was confirmed in quantitative analysis of 5 capillary fields per heart (5 hearts per group, Fig. 6). While cilazaprilat did not affect postischemic plugging, NOLAG further increased it.

\subsubsection{Postcapillary adhesion}

3.2.2.1. Small venules. Postcapillary venular adhesion of PMN was found to be $21 \pm 5$ PMN per $\mathrm{mm}^{2}$ vessel surface area in control experiments. Ischemia induced a marked increase in postcapillary adhesion (Fig. 7). Cilazaprilat reversed this increase to a level not significantly different from control values. NOLAG, however, further increased the ischemia-dependent rise of postischemic ad-

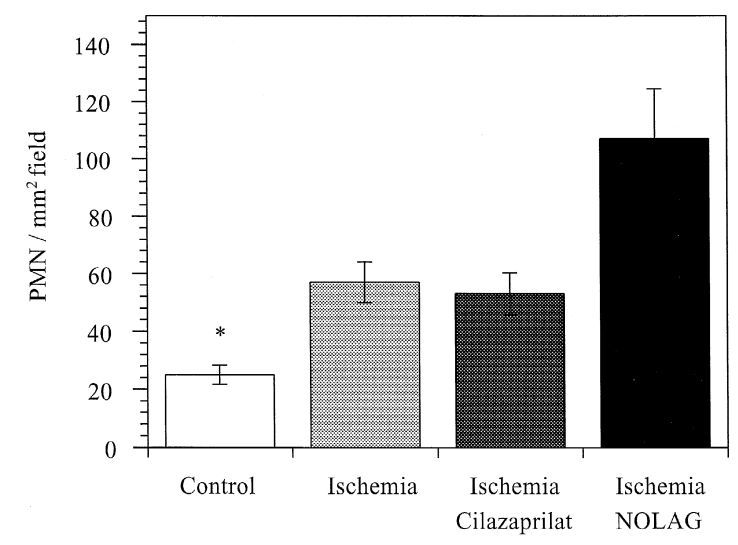

Fig. 6. PMN plugging in capillaries of reperfused hearts. Control $=$ no ischemia; Ischemia $=15 \mathrm{~min}$ of warm ischemia; Cila $=2 \mu \mathrm{M}$ Cilazaprilat, $N O L A G=10 \mu \mathrm{M}$ nitro-L-arginine. Mean \pm SEM. $*=p<0.05$ v. all other groups. 


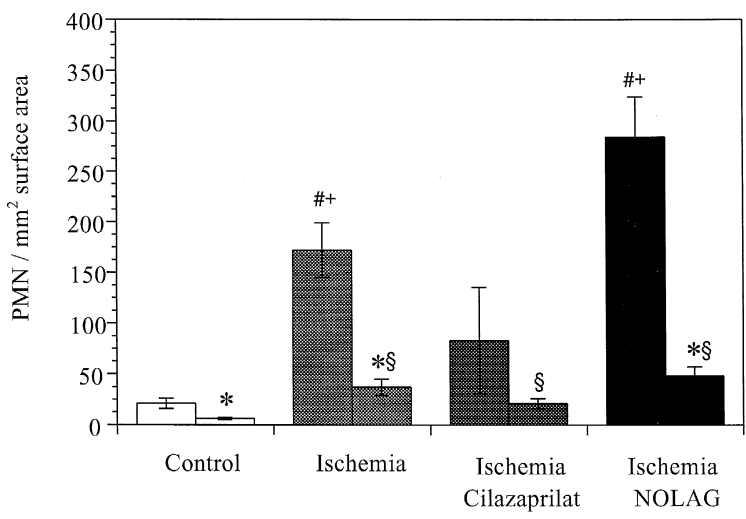

Fig. 7. PMN adhesion in small and large venules in reperfused hearts. Control $=$ no ischemia; Ischemia $=15$ min of warm ischemia; Ischemia + Cila $=15$ min of warm ischemia in the presence of $2 \mu \mathrm{M}$ cilazaprilat, Ischemia $+N O L A G=15 \mathrm{~min}$ of ischemia in the presence of $10 \mu \mathrm{M}$ nitro-L-arginine. Mean \pm SEM. ${ }^{*}=p<0.05 \mathrm{v}$. paired small venule quantity, $\#=p<0.05 \mathrm{v}$. Control in small venules; $+=p<0.05 \mathrm{v}$. Ischemia + Cila in small venules; $\S=p<0.05$ v. Control in big venules.

hesion to more than 13-fold the control level. Fig. 8A and $\mathrm{B}$ show two representative examples of postcapillary adhesion in small venules with either cilazaprilat (Fig. 8A) or NOLAG (Fig. 8B) added to the perfusate.

3.2.2.2. Large venules. Very few PMN were localized in large venules of control hearts $\left(6 \pm 1\right.$ PMN per $\mathrm{mm}^{2}$ vessel surface area). Ischemia induced a rise of PMN adhesion in this class of venules to $37 \pm 8 \mathrm{PMN}$ per $\mathrm{mm}^{2}$ surface area. Cilazaprilat slightly reduced this value $(21 \pm 5$ PMN per $\mathrm{mm}^{2}$ surface area), although no significant effect could be obtained. NOLAG, in contrast, tended to increase postischemic PMN adhesion in the large venules to $48 \pm 9$ PMN per $\mathrm{mm}^{2}$ surface area (Fig. 7). Taken together, these findings suggest that postcapillary adhesion rather than capillary plugging accounts for increased coronary PMN retention after ischemia in the present model. ACE-inhibition reduces, while NOLAG increases adhesion, indicating an antiadhesive effect of nitric oxide.

\subsubsection{Leukocyte activation}

Activation of human leukocytes was further analyzed by quantifying $\mathrm{CD} 11 \mathrm{~b}$ surface expression. As shown in Fig. 9, PMN of control experiments (without ischemia) displayed almost no difference in CD11b surface expression before and after coronary passage. Postischemically, however, a 2.6 fold elevation of CD11b expression had occurred on PMN emerging from the coronary system.

Fig. 8. Examples of postischemic PMN adhesion in small venules. Upper Panel: FITC-fluorescence picture, $1.2 \mathrm{~mm}^{2}$ field. Lower Panel: Rhodamine 6G fluorescence picture showing PMN in venules. A: Representative example of the Ischemia + Cila group; B: Representative example of the Ischemia + NOLAG group.

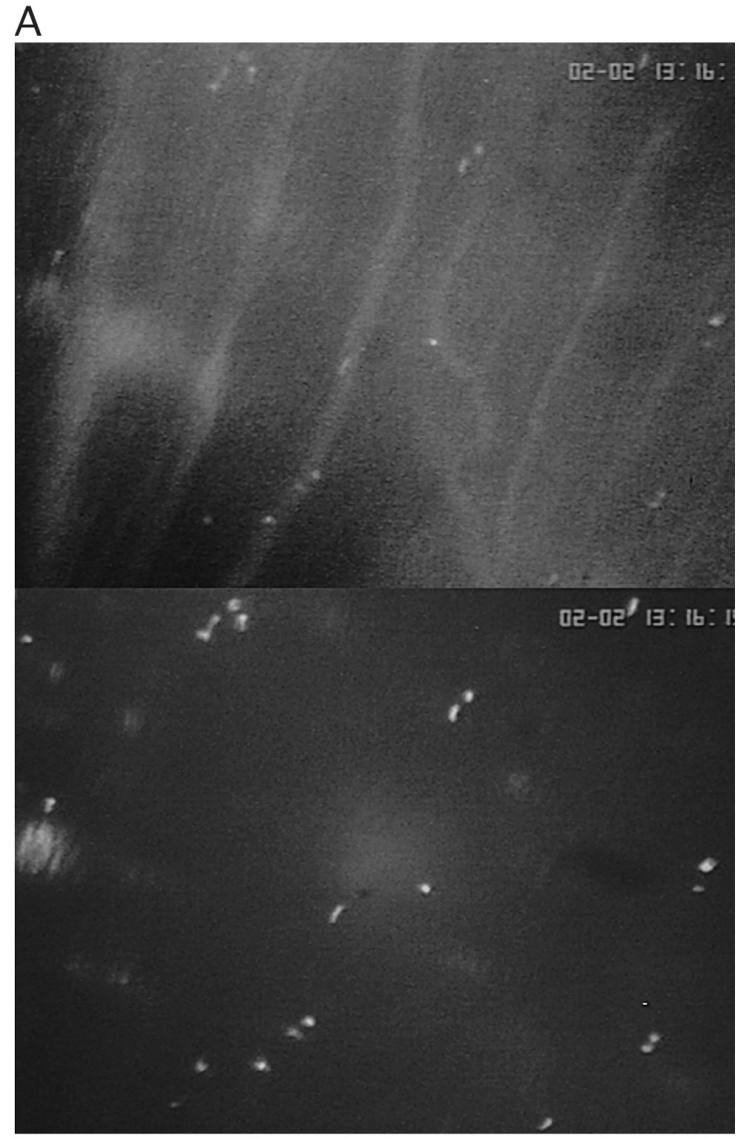

B

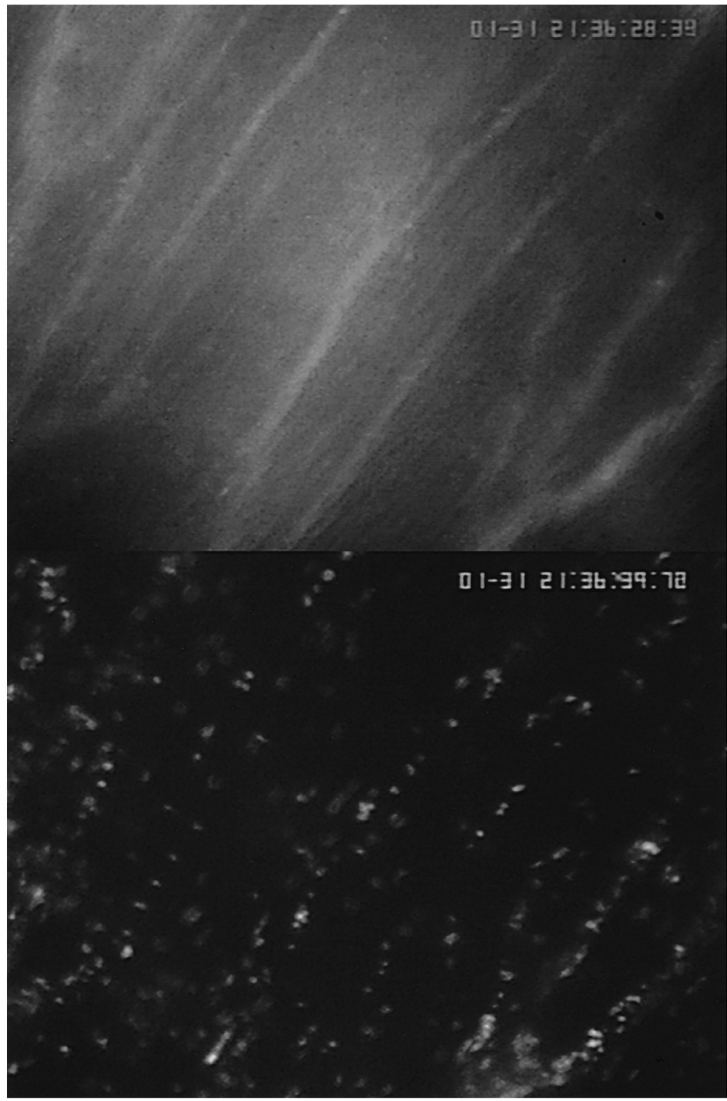




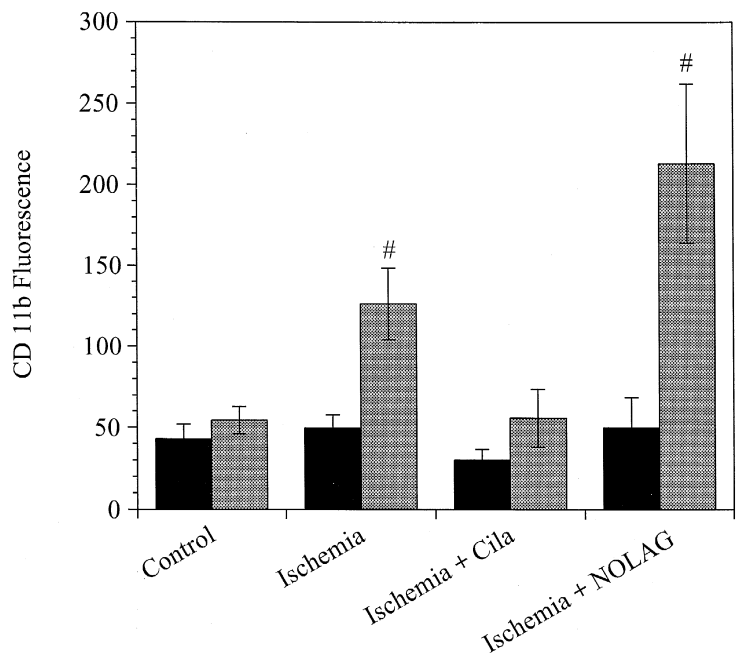

Fig. 9. Leukocyte activation by CD11b expression (FACScan, Becton Dickenson). PMN before coronary passage (hatched bars) and after coronary passage (solid bars) were analyzed. $\#=p<0.05$ v. paired pre-passage value.

When cilazaprilat was present, this increase in CD11b-associated fluorescence intensity was completely abolished, whereas NOLAG further enhanced CD11b expression. These findings indicate that cilazaprilat prevents activation and subsequent postcapillary adhesion, most likely through a nitric oxide mediated mechanism.

\section{Discussion}

Early implementation of ACE inhibition after myocardial infarction has proven beneficial in several models [19-23]. In search of a possible 'local' action to explain this effect, we have previously found ACE-inhibitors to mitigate postischemic functional damage in saline-perfused hearts via a bradykinin and, ultimately, nitric oxide mediated pathway [31]. NO, in turn, is known to mitigate adhesion of PMN in various vascular beds. Since PMN strongly exacerbate post-ischemic damage in the isolated heart model [27,28,31], we set out to investigate the simultaneous occurrence and interdependence of four phenomena: First, the ability of an ACE inhibitor (cilazaprilat) to alleviate postischemic loss of myocardial performance induced by PMN, as opposed to the action of an inhibitor of NO-synthase (nitro-L-arginine). Second, the actual effect of these interventions on postischemic coronary release of nitric oxide. Third, the corresponding changes in PMN adhesion according to specific localization in capillaries, small venules and collecting veins. Fourth, PMN activation during coronary passage in post-ischemic hearts in the presence of cilazaprilat or nitro-L-arginine.

\subsection{Influence of ischemia and reperfusion}

As a result of ischemia and reperfusion alone, isolated hearts suffered from compromised external heart work
(Fig. 3), i.e. myocardial stunning, and a general decline in production of NO (Fig. 4). Both phenomena were aggravated by application of PMN during reperfusion. Reactive oxygen species play a crucial role in this type of reperfusion injury, as shown by others [32] as well as in our model $[27,28]$. Beyond an inherent detrimental effect on cellular processes, reactive oxygen species may enhance interactions between endothelium and PMN by externalization of stored P-selectin and PAF [29,33] as well as by activation and translocalization of the leukocyte receptor Mac-1 (CD11b/CD18) [34]. The latter parameter was the one we chose to observe (Fig. 9). Indeed, we found CD11b expression to be markedly elevated on PMN after passage through the coronary system of post-ischemic hearts. These effects may explain the fast and significant rise of venular leukocyte adhesion immediately after resumption of coronary perfusion, a time at which de novo synthesis of adhesion molecules cannot yet have taken place. We cannot rule out a contribution of plugging leukocytes, which has approximately doubled postischemically (Fig. 6), although the myocardial stunning and loss of endothelial NO-release after ischemia (Figs. 3 and 4) fits best to the steep increase of postcapillary PMN adhesion (Fig. 7).

\subsection{Influence of ACE-inhibition on PMN dependent reper- fusion injury}

Several studies have shown a cardioprotective effect of ACE-inhibition after limited ischemia in vivo and in situ [19-23]. However, this work for the first time presents direct microscopic observations that ACE-inhibition by cilazaprilat can acutely reduce ischemia-induced PMN adhesion and activation in the coronary venules independent of any coronary hemodynamic influence. In parallel experiments, cilazaprilat was capable of blunting PMN dependent loss of myocardial (external heart work) and endothelial function (reduced production of NO).

In the presence of the ACE-inhibitor ramiprilat, Schoelkens and coworkers found an increase in bradykinin concentration immediately after ischemia in isolated rat hearts [35]. Decreased bradykinin degradation due to ACE inhibition leads to a stimulation of endothelial nitric oxide synthase [31]. In this context it is important to point out that NO may act as an antioxidant and radical scavenger, which may interfere with the reperfusion-induced release of oxygen free radicals and, thus, prevent subsequent activation of endothelial cells and PMN [36]. The dependence on NO is made even more probable by the fact that cilazaprilat does not exert a radical scavenging effect itself (data not shown), in contrast to e.g. captopril [37]. With the concentration of cilazaprilat used $(2 \mu \mathrm{M})$, no effects were seen on recovery of external heart work during cell-free reperfusion, as opposed to findings with higher concentrations of a similar drug [24]. The negative effect of NOLAG on myocardial recovery is counteracted by cilazaprilat (Fig. 3) suggesting that in fact cilazaprilat 
really does activate nitric oxide synthase. Interestingly, NO release was maintained by cilazaprilat at a higher level even after PMN application, i.e., the time at which adherent PMN produce tissue damaging radicals and oxidants.

How does the observed impact of cilazaprilat on myocardial and endothelial recovery relate to PMN retention of the hearts? A multitude of factors is able to change the balance of pro- and antiadhesive behaviour of coronary endothelial cells, notably NO [26]. In the presence of cilazaprilat, we observed slightly increased nitric oxide release during early reperfusion, the period in which PMN were injected (Fig. 4). Indeed, PMN, given in the early reperfusion, adhered less in the presence of cilazaprilat (Fig. 7), while, in contrast, capillary plugging was barely influenced (Fig. 6). At this point, however, it cannot be ruled out that nitric oxide formation in the presence of cilazaprilat has additional, indirect effects inhibiting proadhesive mediators formed during reperfusion, e.g. endothelin-1 [38,39].

Since NO release from the whole intact heart is a 'net' effect of nitric oxide production and consumption, the local increase of NO might have been higher but, in part, consumed by oxygen free radicals. The crucial importance of NO for leukocyte adhesion in our model is demonstrated by application of NOLAG, which increased adhesion and activation of PMN (Figs. 8 and 9). NOLAG is a nonspecific NO synthase inhibitor which affects endothelial (eNOS) and inducible nitric oxide synthase (iNOS). However, in primary cultured endothelial cells from isolated rat hearts, we could not detect iNOS by Western blotting (data not shown). Therefore NOLAG most likely affects the eNOS, the same enzyme which is activated in the presence of cilazaprilat.

\section{Conclusions}

In summary, we have investigated the influence of ACE-inhibition on PMN adhesion and myocardial and endothelial function after a PMN bolus given early in reperfusion of isolated hearts. Cilazaprilat mitigated postischemic increase in PMN adhesion, foremost in postcapillary venules. Concomitantly, PMN-induced loss of external heart work and reduction of endothelial nitric oxide release were prevented by cilazaprilat. ACE-inhibition also prevented activation of PMN during passage of the coronary system of postischemic hearts. Inhibition of NO-synthase caused the exact opposite in each case. Thus, the protective effects of ACE inhibition may well be mediated by the oxygen radical scavenging ability of $\mathrm{NO}$ and evolve from reduced adhesion of PMN in the presence of NO.

The findings of the present study underscore the importance of leukocyte adhesion and activation after ischemia. Pharmacological interventions aimed at reducing leukocyte induced reperfusion injury may well benefit those patients who already suffer from compromised myocardial contrac- tility. Recent clinical investigations showing leukocyte activation in man as a potential risk factor of recurrent coronary events enforce this approach [40].

\section{Acknowledgements}

Cilazaprilat was a gift of Hofmann La Roche (Basel, Switzerland), which also provided the WPI nitric oxide sensor. The study was supported in part by the FriedrichBaur-Foundation of the University of Munich. We thank Veronika Frei for expert technical assistance.

\section{References}

[1] Braunwald E, Kloner RA. The stunnned myocardium: Prolonged, postischemic ventricular dysfunction. Circulation 1982;66:11461149.

[2] Bolli R, Patel BS, Hartley CJ, Thormbvy JI, Jeroudi MO, Roberts R. Nonuniform transmural recovery of contractile function in stunned myocardium. Am J Physil 1989;257:H375-385.

[3] Seccombe JF, Schaff HV. Coronary artery endothelial function after myocardial ischemia and reperfusion. Ann Thorac Surg 1995;60:778-788.

[4] Maes A, Van de Werf F, Nuyts J, Bormans G, Desmet W, Mortelmans L. Impaired myocardial tissue perfusion early after successful thrombolysis. Impact on myocardial flow, metabolism, and function at late follow up. Circulation 1995;92:2072-2078.

[5] Ragosta M, Camarano G, Kaul S, Powers ER, Sarembock IJ, Gimple LW. Microvascular integrity indicates myocellular viability in patients with recent myocardial infarction. New insights using myocardial contrast echocardiography, Circulation 1994;89:25622569.

[6] Sawa Y, Taniguchi K, Kadoba K, Nishimura M, Ichikawa H, Amemiya A, Kuratani T, Matsuda H. Leukocyte depletion attenuates reperfusion injury in patients with left ventricular hypertrophy. Circulation 1996;93:1640-1646.

[7] Chatelain P, Latour J-G, Tran D, De Lorgeril M, Dupras G, Bourassa M. Neutrophil accumulation in experimental myocardial infarcts: relation with extent of injury and effect of reperfusion. Circulation 1987;75:1083-1090.

[8] Go LO, Murry CE, Richard VK, Weischedel GR, Jennings RB, Reimer KA. Myocardial neutrophil accumulation during reperfusion after reversible or irreversible ischemic injury. Am J Physiol 1988;255:H1188-1198.

[9] Kraemer R, Mullane KM. Neutrophils delay functional recovery of the post-hypoxic heart of the rabbit. J Pharmacol Exp Ther 1989;251:620-626.

[10] Tanaka M, Brooks SE, Richard VJ, FitzHarris GP, Stoler RC, Jennings RB, Arfors KE, Reimer KA. Effect of anti-CD18 antibody on myocardial neutrophil accumulation and infarct size after ischemia and reperfusion in dogs. Circulation 1993;87:526-535.

[11] Sheridan FM, Cole PG, Ramage MS. Leukocyte adhesion to the coronary microvasculature during ischemia and reperfusion in an in vivo canine model. Circulation 1996;63:1784-1787.

[12] Shandelya SML, Kuppusamy P, Weisfeldt ML, Zweier JL. Evaluation of the role of polymorphonuclear leukocytes on contractile function in myocardial reperfusion injury. Circulation 1993;87:536546.

[13] Smith EF III, Egan JW, Bugelski PJ, Hillegass LM, Hill DE, Griswold DE. Temporal relation between neutrophil accumulation and myocardial reperfusion injury. Am J Physiol 1988;255:H10601068. 
[14] Schmid-Schönbein G. Capillary plugging by granulocytes and the no-reflow phenomenon in the microcirculation. Fed Proc 1987;46:2397-2401.

[15] Simpson PJ, Todd RF, Fantone JC, Mickelson JK, Griffin JD, Lucchesi BR. Reduction of experimental canine myocardial reperfusion injury by a monoclonal antibody (anti-Mo1, anti-CD11b) that inhibits leukocyte adhesion. J Clin Invest 1988;81:624-629.

[16] Lefer DJ, Shandelya SML, Serrano CV, Becker LC, Kuppusamy P, Zweier JL. Cardioprotective actions of a monoclonal antibody against CD-18 in myocardial ischemia-reperfusion injury. Circulation 1993;88:1779-1787.

[17] von Andrian UH, Chambers JD, McEvoy LM, Bargatze RF, Arfors KE, Butcher EC. Two-step model of leukocyte-endothelial cell interaction in inflammation: distinct roles for LECAM-1 and the leukcyte $\beta_{2}$-integrins in vivo. Proc Natl Acad Sci USA 1991;88:7538-7542.

[18] Carlos TM, Harlan JM. Leukocyte-endothelial adhesion molecules. Blood 1994;84:2068-2101.

[19] Hartman JC, Wall TM, Hullinger TG, Shebuski R. Reduction of myocardial infarct size in rabbits by ramiprilat: reversal by the bradykinin antagonist HOE 140. J Cardiovasc Pharmacol 1993;21:996-1003.

[20] Di Pasquale P, Paterna S, Valenza M, Valdes L, Albano V, Trombino G, Vitrano G, Cannizzaro S, Licata G, Albiero R. Effects of captopril on myocardial protection during cardioplegia. Int J Cardiol 1993;42:225-230.

[21] Zughaib ME, Sun JZ, Bolli R. Effect of angiotensin-converting enzyme inhibitors on myocardial ischemia/reperfusion injury: an overview. Basic Res Cardiol 1993;88:155-167.

[22] Muller CAM, Opie LH, Peisach M, Pineda CA. Chronic oral pretreatment with the angiotensin converting enzyme inhibitor, trandolapril, decreases ventricular fibrillation in acute ischaemia and reperfusion. Eur Heart J 1994;15:988-996.

[23] Kitakaze M, Minamino T, Node K, Komamura K, Shinozaki Y, Mori H, Kosaka H, Inoue M, Hori M, Kamada T. Beneficial effects of inhibition of angiotensin-converting enzyme on ischemic myocardium during coronary hypoperfusion in dogs. Circulation 1995;92:950-961.

[24] Massoudy P, Becker BF, Gerlach E. Bradykinin accounts for improved postischemic function and decreased glutathione release of guinea pig heart treated with the angiotensin-converting enzyme inhibitor ramiprilat. J Cardiovasc Pharmacol 1994;23:632-639.

[25] Tanonaka K, Kamiyama T, Takezono A, Sakai K, Takeo S. Beneficial effects of angiotensin I converting enzyme inhibitor on postischemic contractile function of perfused rat heart. J Mol Cell Cardiol 1996;28:1659-1670.

[26] Kubes P, Suzuki M, Granger DN. Nitric oxide: an endogenous modulator of leukocyte adhesion. Proc Natl Acad Sci USA 1991;88:4651-4655.

[27] Raschke P, Becker BF, Leipert B, Schwartz LM, Zahler S, Gerlach E. Postischemic dysfunction of the heart induced by small numbers of neutrophils via formation of hypochlorous acid. Basic Res Cardiol 1993;88:321-339.

[28] Kupatt C, Zahler S, Seligmann C, Massoudy P, Becker BF, Gerlach E. Nitric oxide mitigates leukocyte adhesion and vascular leak after myocardial ischemia. J Mol Cell Cardiol 1996;28:643-654.

[29] Zahler S, Kowalski C, Brosig A, Kupatt C, Becker BF, Gerlach E. The function of neutrophils isolated by a magnetic antibody cell separation technique is not altered in comparison to a density gradient method. J Immunol Meth 1997;200:173-179.

[30] Raschke P, Becker BF. Adenosine and PAF dependent mechanisms lead to myocardial reperfusion injury by neutrophils after brief ischemia. Cardiovasc Res 1995;29:569-576.

[31] Massoudy P, Becker BF, Gerlach E. Nitric oxide accounts for postischemic cardioprotection resulting from angiotensin-converting enzyme inhibition: indirect evidence for a radical scavenger effect in isolated guinea pig heart. J Cardiovasc Pharmacol 1995;25:440-447.

[32] Bolli R, Jeroudi MO, Patel BS, DuBose CM, Lai EK, Roberts R, McKay PB. Direct evidence that oxygen-derived free radicals contribute to postischemic myocardial dysfunction in the intact dog. Proc Natl Acad Sci USA 1989;86:4695-4699.

[33] Lewis MS, Whatley RE, Cain P, McIntyre TM, Prescott SM, Zimmerman GA. Hydrogen peroxide stimulates the synthesis of platelet-activating factor by endothelium and induces endothelial cell-dependent neutrophil adhesion. J Clin Invest 1988;82:20452055.

[34] Fraticelli A, Serrano CV, Bochner BS, Capogrossi MC, Zweier JL. Hydrogen peroxide and superoxide modulate leukocyte adhesion molecule expression and leukocyte endothelial adhesion. Biochim Biophys Acta 1996;1310:251-259.

[35] Baumgarten CR, Linz W, Kunkel G, Schoelkens BA, Wiemer G. Ramiprilat increases bradykinin outflow from isolated hearts of rat. Br J Pharmacol 1993;108:293-295.

[36] Suematsu M, Tamatani T, Delano FA, Miyasaka M, Forrest M, Suzuki H, Schmid-Schonbein GW. Microvascular oxidative stress preceding leukocyte activation elicited by in vivo nitric oxide suppression. Am J Physiol 1994;266:H2410-2415.

[37] Aruoma OI, Akanmu D, Cecchini R, Halliwell B. Evaluation of the ability of the angiotensin-converting enzyme inhibitor captorpil to scavenge reactive oxygen species. Chem Biol Interact 1991;77:303314.

[38] Hughes AK, Stricklett PK, Padilla E, Kohan DE. Effect of reactive oxygen sepcies on endothelin-1 production by human mesangial cells. Kidney Int 1996;49:181-189.

[39] Brunner F, Kukovetz WR. Postischemic antiarrhythmic effects of angiotensin-converting enyme inhibitors. Circulation 1996;94:17521761.

[40] Mickelson JK, Lakkis NM, Villarreal-Levy G, Hughes BJ, Smith $\mathrm{CW}$. Leukocyte activation with platelet adhesion after coronary angioplasty: a mechanism for recurrent disease. J Am Coll Cardiol 1996;28:345-353. 